\title{
Risk factors for esophageal fistula in patients with locally advanced esophageal carcinoma receiving chemoradiotherapy
}

This article was published in the following Dove Press journal:

OncoTargets and Therapy

\section{Yang Zhangl,* \\ Zongjuan $\mathrm{Li}^{2}$,* \\ Wei Zhangl,* \\ Wei Chen' \\ Yipeng Song'}

'Department of Radiation Oncology, Qingdao University Medical College Affiliated Yantai Yuhuangding Hospital, Yantai, Shandong, People's Republic of China; ${ }^{2}$ Department of Radiation Oncology, The Second Hospital of Dalian Medical University, Dalian, Liaoning, People's Republic of China

*These authors contributed equally to this work
Correspondence: Yipeng Song Department of Radiation Oncology, Qingdao University Medical College Affiliated Yantai Yuhuangding Hospital, No 20, Yuhuangding East Road, Yantai, Shandong 264000, People's Republic of China

$\mathrm{Tel}+8653167626162$

Fax +86 53। 87984079

Emailsyp1972@sina.com
Background: This study aimed to investigate risk factors for esophageal fistula in patients with locally advanced esophageal carcinoma receiving chemoradiotherapy.

Subjects and methods: The study prospectively enrolled 212 esophageal carcinoma patients undergoing chemoradiotherapy and evaluated 16 clinical parameters. The best cut-off values were determined by receiver operating characteristics curves. Hazard ratios (HR) and $95 \%$ confidence intervals (CIs) were calculated by the Cox proportional hazards model. Kaplan-Meier analysis was used to evaluate the cumulative probability.

Results: In total, 22 patients (10.38\%) developed esophageal fistula, of whom 9 experienced fistula during treatment and the other 13 patients developed fistula after chemoradiotherapy. The median time until occurrence was 5.75 months (range 0.6-8 months). In univariate analysis, the evaluated significant factors were Karnofsky performance status, smoking status, esophageal stenosis, $\mathrm{T}$ stage, fraction dose, and carcinoembryonic antigen (CEA). In addition, esophageal stenosis $(\mathrm{HR}=4.089,95 \%$ CI 1.451-11.527, $p=0.008)$, T stage $(\mathrm{HR}=2.663,95 \%$ CI $1.019-6.960$, $p=0.046)$, and CEA $(\mathrm{HR}=0.309,95 \%$ CI $0.124-0.768, p=0.011)$ were revealed as risk parameters in further multivariate analysis.

Conclusion: This is the first prospective study to evaluate factors associated with fistula formation in patients with esophageal carcinoma receiving chemoradiotherapy. More attention should be given to patients with esophageal stenosis, stage T4 disease, and high levels of CEA.

Keywords: esophageal fistula, esophageal carcinoma, chemoradiotherapy, side effect, risk factors

\section{Introduction}

According to the statistics of the National Cancer Center, esophageal carcinoma (EC) has become the third most common cancer and the fourth leading cause of cancerrelated deaths in People's Republic of China. ${ }^{1}$ Radical surgery is a mainstay measure for localized EC. However, owing to a lack of early screening, up to $30 \%-40 \%$ patients in People's Republic of China missed the opportunity for radical surgery. For these people, the Radiation Therapy Oncology Group trial 85-01 and subsequent research demonstrated that chemoradiotherapy was the first choice treatment. ${ }^{2-5}$

Despite the improvements in local control and long-term survival rates of EC, it is still limited by several side effects. Notably, esophageal fistula (Figure 1) is one of the most serious complications.

Esophageal fistula is caused by tumor-related and non-tumor-related issues. Anatomically, the esophagus is surrounded by mediastinum, bronchi, lungs, and blood vessels, which could be directly invaded by advanced EC. In addition, chemoradiotherapy 

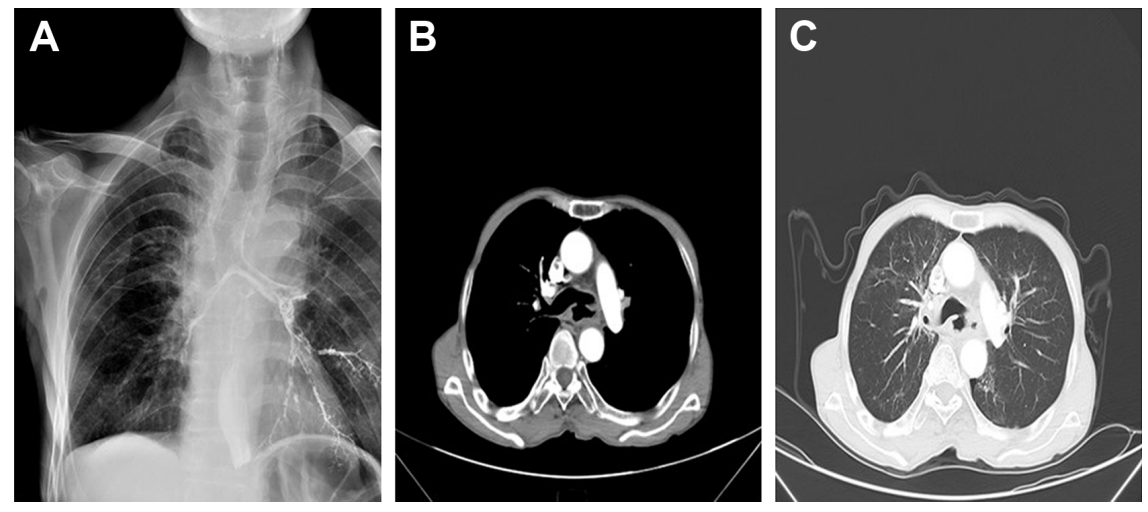

Figure I Representative radiographic images of esophageal fistula.

Notes: (A) Barium flows into bronchus on barium meal X-ray examination; (B) The tumor penetrates through the esophagus wall in mediastinal window; (C) The tumor penetrates through the esophagus wall in lung window.

can induce esophageal fistula owing to the imbalance between tumor shrinkage and the normal tissue repair system. ${ }^{6,7}$

The incidence of esophageal fistula in EC patients receiving chemoradiotherapy has been reported to be $6 \%-22 \% .^{2,8-12}$ The prognosis of esophageal fistula is very poor. According to the data in previous studies, the mean survival time was only 2-2.5 months. ${ }^{13,14}$ The current treatment strategies for esophageal fistula are not favorable, so prevention should be given more attention.

Although the factors associated with esophageal fistula are clinically significant, they have not been well elucidated. Therefore, we performed this prospective study to determine the relevant risk factors.

\section{Subjects and methods Patients}

This study was approved by the Institutional Review Board of The Second Hospital of Dalian Medical University (TSHDMU20140823), and written informed consent was obtained from each patient before treatment.

Between September 2014 and September 2016, 212 initially diagnosed EC patients in our institute were enrolled in the study. The patients were selected according to the following criteria: 1) pathologically diagnosed esophageal squamous cell carcinoma; 2) staged as II-III based on the American Joint Committee on Cancer, 7th edition; 3) treated by intensity-modulated radiotherapy (IMRT) and chemotherapy; and 4) Karnofsky performance status (KPS) $\geq 70$. Patients with the following criteria were excluded from the cohorts: 1) previously underwent esophageal surgery or thoracic radiotherapy; 2) concomitant with other advanced carcinoma; and/or 3) lost to follow-up.

\section{Pretreatment examination}

Pretreatment evaluation included a physical examination; magnetic resonance imaging of the head; esophagus barium meal examination; esophagoscope and endoscopic ultrasonography; pathological examination; contrast-enhanced computed tomography (CT) of the cervical region, chest, and abdomen; tumor markers; blood corpuscle analysis; and other essential tests. The tumors were staged based on the $\mathrm{CT}$ and endoscopic ultrasonography examinations.

\section{Therapeutic regimen}

One of the following 2 chemotherapy regimens was adopted. The first was the TP scheme, consisting of intravenous infusion of docetaxel (TXT) $50 \mathrm{mg} / \mathrm{m}^{2} /$ day on days 1 and 15 , combined with cisplatin (DDP) $50 \mathrm{mg} / \mathrm{m}^{2} /$ day on days 1 and 15. The second was the PF scheme, consisting of protracted infusion of 5-fluorouracil (5-FU) 1,000 mg/m²/day on days $1-5$ and DDP $75 \mathrm{mg} / \mathrm{m}^{2} /$ day on day 1 . Both schemes were repeated after 28 days.

All patients in the study received IMRT. The radiation dose was delivered with linear accelerators using $6 \mathrm{MV}$ $\mathrm{X}$-rays. Each patient was given a daily fraction of 1.8-2.0 Gy administered on 5 days per week up to a total dose of 59.4 or $60 \mathrm{~Gy}$.

\section{Data collection}

Information including demographics, tumor and treatmentrelated data was analyzed. Information on pretreatment status of tumor markers, body mass index (BMI), KPS, smoking, and concomitant disease was also collected. The detailed information about the associated parameters is shown in Table 1. The formula for BMI is weight in kilograms divided by height in meters squared. Smoking status was measured by the cigarette smoking index (CSI), which is equal to the number of cigarettes consumed per day multiplied by the number of years of smoking. Esophageal stenosis was measured according to the clinical symptoms and graded based on the criteria in Table 2. In this study, esophageal stenosis was defined as $\geq$ grade 2 . 
Table I Clinical characteristics of patients

\begin{tabular}{|c|c|c|}
\hline Characteristic & Number (\%) & $\begin{array}{l}\text { Number of } \\
\text { events (\%) }\end{array}$ \\
\hline \multicolumn{3}{|l|}{ Gender } \\
\hline Male & $173(81.60)$ & $21(12.14)$ \\
\hline Female & $39(18.40)$ & I $(2.60)$ \\
\hline \multicolumn{3}{|l|}{ Age (years) } \\
\hline$>60$ & $100(47.17)$ & $10(10)$ \\
\hline$\leq 60$ & $112(52.83)$ & $12(10.71)$ \\
\hline \multicolumn{3}{|l|}{ KPS } \\
\hline$>80$ & $129(60.85)$ & $9(7.10)$ \\
\hline$\leq 80$ & $83(39.15)$ & $13(15.66)$ \\
\hline \multicolumn{3}{|l|}{ BMI $\left(\mathrm{kg} / \mathrm{m}^{2}\right)$} \\
\hline$>24$ & $75(35.38)$ & $5(6.67)$ \\
\hline$\leq 24$ & $137(64.62)$ & $17(12.41)$ \\
\hline \multicolumn{3}{|l|}{ Smoking status (CSI) } \\
\hline$>600$ & $57(26.89)$ & II (19.30) \\
\hline$\leq 600$ & $155(73.11)$ & II (7.10) \\
\hline \multicolumn{3}{|l|}{ Hypertension } \\
\hline No & I6I (75.94) & $15(9.32)$ \\
\hline Yes & $5 I(24.06)$ & $7(13.73)$ \\
\hline \multicolumn{3}{|l|}{ Ulcerative tumor } \\
\hline No & $142(66.98)$ & $12(8.45)$ \\
\hline Yes & $70(33.02)$ & $10(14.29)$ \\
\hline \multicolumn{3}{|l|}{ Esophageal stenosis } \\
\hline No & $107(50.47)$ & $5(4.67)$ \\
\hline Yes & $105(49.53)$ & $17(16.19)$ \\
\hline \multicolumn{3}{|l|}{ Tumor location } \\
\hline Cervical + upper & $84(39.63)$ & $8(9.52)$ \\
\hline Middle + lower & $128(60.38)$ & $14(10.94)$ \\
\hline \multicolumn{3}{|l|}{ T stage } \\
\hline $2-3$ & $180(84.91)$ & 14 (7.78) \\
\hline 4 & $32(15.09)$ & $8(25.00)$ \\
\hline \multicolumn{3}{|l|}{$N$ stage } \\
\hline $0-2$ & $204(96.23)$ & $10(4.90)$ \\
\hline 3 & $8(3.77)$ & $2(25.00)$ \\
\hline \multicolumn{3}{|l|}{ Treatment modality } \\
\hline Sequential & $135(63.68)$ & 14 (10.37) \\
\hline Concurrent & 77 (36.32) & $8(10.39)$ \\
\hline \multicolumn{3}{|l|}{ Fraction dose (Gy) } \\
\hline 1.8 & 57 (26.89) & $10(17.54)$ \\
\hline 2.0 & $155(73.11)$ & $12(7.74)$ \\
\hline \multicolumn{3}{|c|}{ Chemotherapy regimen } \\
\hline TP & $140(66.04)$ & $10(7.14)$ \\
\hline PF & $72(33.96)$ & $12(16.67)$ \\
\hline \multicolumn{3}{|l|}{ CEA (ng/mL) } \\
\hline$>2.87$ & $65(30.66)$ & $12(18.46)$ \\
\hline$\leq 2.87$ & $147(69.34)$ & $10(6.80)$ \\
\hline \multicolumn{3}{|l|}{ Cyfra2I-I (ng/mL) } \\
\hline$>3.64$ & $76(35.85)$ & $12(15.79)$ \\
\hline$\leq 3.64$ & $136(64.15)$ & $10(7.35)$ \\
\hline
\end{tabular}

Abbreviations: KPS, Karnofsky performance status; BMI, body mass index; CSI, cigarette smoking index; TP, docetaxel and cisplatin; PF, cisplatin and 5-fluorouracil; CEA, carcinoembryonic antigen.

\section{Follow-up}

All patients were evaluated during the course of therapy and 30 days after treatment. Then, they were followed up every 3 months, unless they had emergent symptoms which needed immediate medical intervention. At each follow-up visit, radiographic examinations including an esophagus barium meal examination and contrast-enhanced CT of the cervical
Table 2 Dysphagia scoring system

\begin{tabular}{ll}
\hline Grade & Symptom \\
\hline 0 & Able to eat normal diet/no dysphagia \\
1 & Able to swallow some solid foods \\
2 & Able to swallow only semi-solid foods \\
3 & Able to swallow only liquids \\
4 & Unable to swallow anything/total dysphagia \\
\hline
\end{tabular}

region, chest, and abdomen were usually performed. Esophageal fistula was defined according to Common Terminology Criteria for Adverse Events (CTCAE) 4.0.

\section{Statistical analysis}

The occurrence of esophageal fistula was determined as the final event. The time to the final event was defined as the interval from the start of treatment to the end point. The best cut-off values were determined by the receiver operating characteristics curve. HRs and 95\% CIs were calculated by the Cox proportional hazards model. In addition, Kaplan-Meier analysis was used to evaluate the cumulative probability of esophageal fistula. Parameters with a $p$-value $<0.05$ were included in the multivariate analysis. A 2-sided $p$-value $<0.05$ was recognized as statistically significant in all analyses.

\section{Results Patient features}

In total, 212 patients (173 males and 39 females) were enrolled in the present study. The mean age at diagnosis was 61.3 years (range $42-89$ years). Of the whole study cohort, $24.06 \%$ had hypertension, $33.02 \%$ had ulcerative tumor, and $49.53 \%$ had esophageal stenosis. All patients in this research were treated with chemoradiotherapy (77 received concurrent modality and 135 received sequential modality). A TXT and DDP (TP) chemoregimen was used in 140 patients and 5-FU and DDP (PF) in 72 patients. The detailed clinical information is shown in Table 1.

In our cohort, 22 patients (10.38\%) developed esophageal fistula. Among them, 9 people experienced fistula during treatment, while the other 13 developed fistula after the completion of chemoradiotherapy. The median time of occurrence was 5.75 months (range $0.6-8$ months). The types of esophageal fistula in this study included esophagorespiratory ( 8 patients) and esophageal-mediastinum fistula (14 patients).

At the last follow-up, all 22 patients with fistula had died; the mean survival time was 3.2 months from the development of fistula. Of these, 15 (68.2\%) died from fistula-related adverse events. The most common cause was uncontrollable infection, which occurred in 12 cases. The second most common cause was bleeding, with 3 patients dying from this. 


\section{Risk parameters for fistula development}

Table 3 shows the results of univariate analysis. Among the parameters tested in the research, KPS, smoking status, esophageal stenosis, T stage, fraction dose, and carcinoembryonic antigen (CEA) were evaluated as significant factors,

Table 3 Univariate analysis of the factors associated with esophageal fistula

\begin{tabular}{|c|c|c|c|}
\hline Characteristic & OR & $95 \% \mathrm{Cl}$ & $p$-value \\
\hline \multicolumn{4}{|l|}{ Gender } \\
\hline Male & I & & \\
\hline Female & 0.229 & $0.031-1.700$ & 0.149 \\
\hline \multicolumn{4}{|l|}{ Age (years) } \\
\hline$>60$ & 1 & & \\
\hline$\leq 60$ & 0.992 & $0.428-2.300$ & 0.985 \\
\hline \multicolumn{4}{|l|}{ KPS } \\
\hline$>80$ & I & & \\
\hline$\leq 80$ & 2.411 & $1.032-5.648$ & 0.042 \\
\hline \multicolumn{4}{|l|}{ BMI $\left(\mathrm{kg} / \mathrm{m}^{2}\right)$} \\
\hline$>24$ & 1 & & \\
\hline$\leq 24$ & 1.849 & $0.682-5.013$ & 0.227 \\
\hline \multicolumn{4}{|l|}{ Smoking status (CSI) } \\
\hline$>600$ & I & & \\
\hline$\leq 600$ & 0.380 & $0.165-0.877$ & 0.023 \\
\hline \multicolumn{4}{|l|}{ Hypertension } \\
\hline No & I & & \\
\hline Yes & 1.570 & $0.640-3.853$ & 0.325 \\
\hline \multicolumn{4}{|l|}{ Ulcerative tumor } \\
\hline No & 1 & & \\
\hline Yes & 1.658 & $0.716-3.838$ & 0.238 \\
\hline \multicolumn{4}{|l|}{ Esophageal stenosis } \\
\hline No & 1 & & \\
\hline Yes & 3.672 & $1.354-9.955$ & 0.011 \\
\hline \multicolumn{4}{|l|}{ Tumor location } \\
\hline Cervical + upper & I & & \\
\hline Middle + lower & 1.190 & $0.499-2.838$ & 0.695 \\
\hline \multicolumn{4}{|l|}{ T stage } \\
\hline $2-3$ & I & & \\
\hline 4 & 3.515 & $1.472-8.390$ & 0.005 \\
\hline \multicolumn{4}{|l|}{$N$ stage } \\
\hline $0-2$ & 1 & & \\
\hline 3 & 2.202 & $0.5 \mid 4-9.433$ & 0.288 \\
\hline \multicolumn{4}{|l|}{ Treatment modality } \\
\hline Sequential & 1 & & \\
\hline Concurrent & 1.040 & $0.436-2.480$ & 0.929 \\
\hline \multicolumn{4}{|l|}{ Fraction dose (Gy) } \\
\hline 1.8 & 1 & & \\
\hline 2.0 & 0.416 & $0.180-0.963$ & $0.04 I$ \\
\hline \multicolumn{4}{|c|}{ Chemotherapy regimen } \\
\hline TP & 1 & & \\
\hline PF & 2.189 & $0.945-5.067$ & 0.067 \\
\hline \multicolumn{4}{|l|}{ CEA $(\mathrm{ng} / \mathrm{mL})$} \\
\hline$>2.87$ & 1 & & \\
\hline$\leq 2.87$ & 0.373 & $0.161-0.863$ & 0.021 \\
\hline \multicolumn{4}{|l|}{ Cyfra2I-I (ng/mL) } \\
\hline$>3.64$ & 1 & & \\
\hline$\leq 3.64$ & 0.458 & $0.198-1.060$ & 0.068 \\
\hline
\end{tabular}

Abbreviations: KPS, Karnofsky performance status; BMI, body mass index; CSI, cigarette smoking index; TP, docetaxel and cisplatin; PF, cisplatin and 5-fluorouracil; CEA, carcinoembryonic antigen.
Table 4 Multivariate analysis of risk factors associated with esophageal fistula

\begin{tabular}{|c|c|c|c|}
\hline Characteristic & OR & $95 \% \mathrm{Cl}$ & $p$-value \\
\hline \multicolumn{4}{|l|}{ KPS } \\
\hline$>80$ & 1 & & \\
\hline$\leq 80$ & 2.038 & $0.805-5.160$ & 0.133 \\
\hline \multicolumn{4}{|c|}{ Smoking status (CSI) } \\
\hline$>600$ & I & & \\
\hline$\leq 600$ & 0.543 & $0.220-1.338$ & 0.185 \\
\hline \multicolumn{4}{|c|}{ Esophageal stenosis } \\
\hline No & 1 & & \\
\hline Yes & 4.089 & $1.45 \mathrm{I}-11.527$ & 0.008 \\
\hline \multicolumn{4}{|l|}{ T stage } \\
\hline $2-3$ & I & & \\
\hline 4 & 2.663 & $1.019-6.960$ & 0.046 \\
\hline \multicolumn{4}{|c|}{ Fraction dose (Gy) } \\
\hline 1.8 & 1 & & \\
\hline 2.0 & 0.698 & $0.277-1.763$ & 0.447 \\
\hline \multicolumn{4}{|l|}{ CEA (ng/mL) } \\
\hline$>2.87$ & I & & \\
\hline$\leq 2.87$ & 0.309 & $0.124-0.768$ & 0.011 \\
\hline
\end{tabular}

Abbreviations: KPS, Karnofsky performance status; BMI, body mass index; CSI, cigarette smoking index; TP, docetaxel and cisplatin; PF, cisplatin and 5-fluorouracil; CEA, carcinoembryonic antigen.

while gender, age, BMI, hypertension, ulcerative tumor, tumor location, $\mathrm{N}$ stage, treatment modality, chemotherapy regiments, and cyfra21-1 were not found to be statistically significant. The significant variables were further included in multivariate analysis. Esophageal stenosis $(\mathrm{HR}=4.089$, 95\% CI 1.451-11.527, $p=0.008)$, T stage ( $\mathrm{HR}=2.663,95 \%$ CI $1.019-6.960, p=0.046)$, and CEA (HR $=0.309,95 \%$ CI $0.124-0.768, p=0.011$ ) were revealed as risk factors for fistula formation. The detailed information is shown in Table 4.

We further performed Kaplan-Meier analysis to calculate the cumulative risk of the 3 risk parameters. The cumulative incidence of fistula in patients with esophageal stenosis was $16.19 \%$, which was significantly higher compared with $4.67 \%$ in patients without esophageal stenosis $(p=0.006)$ (Figure 2). The cumulative incidence of fistula in patients with $\mathrm{T} 4$ was $25.0 \%$, which was considerably higher compared with 7.78\% in patients with T2-3 ( $p=0.002)$ (Figure 3). The cumulative incidences of fistula for patients with $\mathrm{CEA}>2.87 \mathrm{ng} / \mathrm{mL}$ and CEA $\leq 2.87 \mathrm{ng} / \mathrm{mL}$ were $18.46 \%$ and $6.8 \%$, respectively $(p=0.016$ ) (Figure 4$)$. For patients with no, 1 , and 2 or 3 risk factors, the actuarial risks for developing fistula were $0 \%, 9.73 \%$, and $25.58 \%$, respectively $(p=0.000)$ (Figure 5). It is obvious that patients with more risk factors are at a higher risk of developing fistula.

\section{Discussion}

Esophageal fistula is one of the most serious complications of EC. The incidence rate for this event has been reported to 


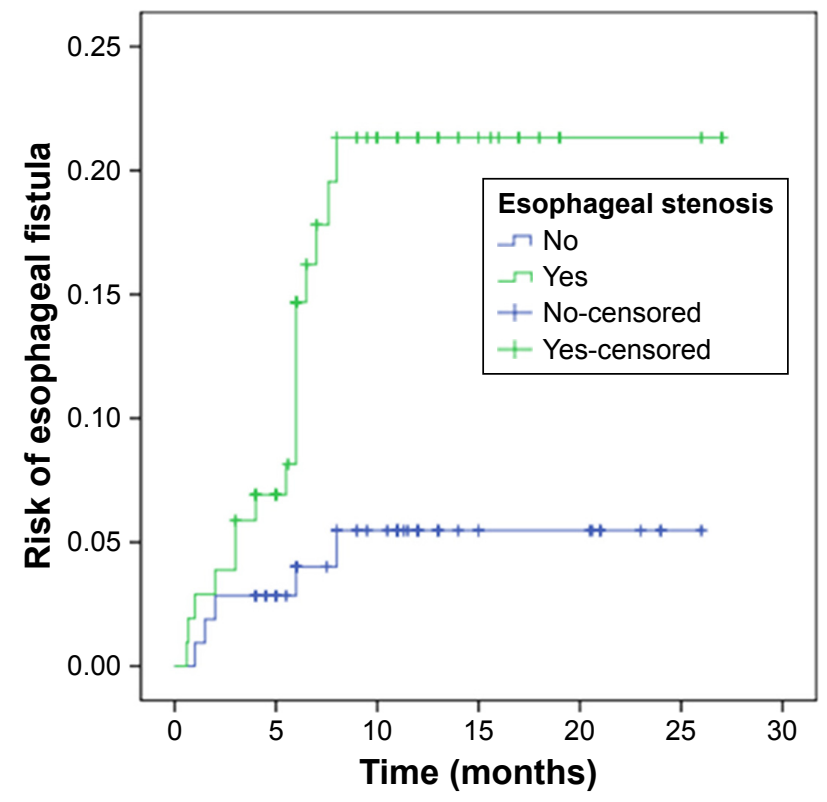

Figure 2 Comparison of the risk of fistula development between patients with and without stenosis $(p=0.006)$.

be $6 \%-22 \%$. Once it occurs, the prognosis is very poor, no matter what kind of strategies are implemented. According to previous data, the mean survival time was only $2-2.5$ months. In our research, the mean survival time was 3.2 months. Thus, compared with treatment, more attention ought to be given to prevention. So far, data on associated parameters are lacking. Only a few articles can be found in the databases. ${ }^{11,15}$ Furthermore, there are several limitations in these articles, such as that the sample sizes are small and the parameters investigated are very limited. Therefore, we performed this

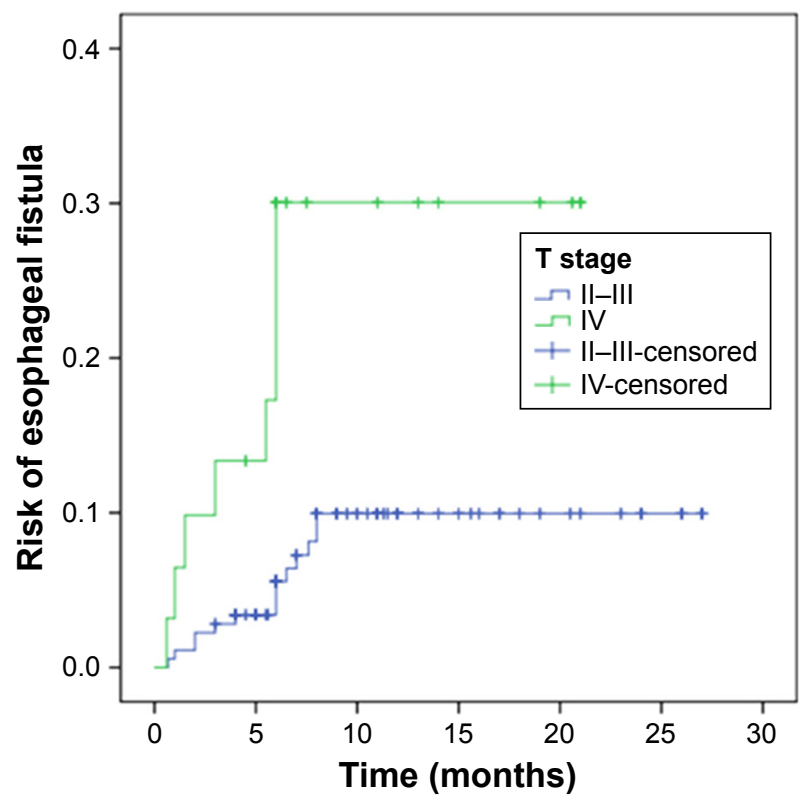

Figure 3 Comparison of the risk of fistula development between patients with stage T2-3 and T4 esophageal carcinoma $(p=0.002)$.

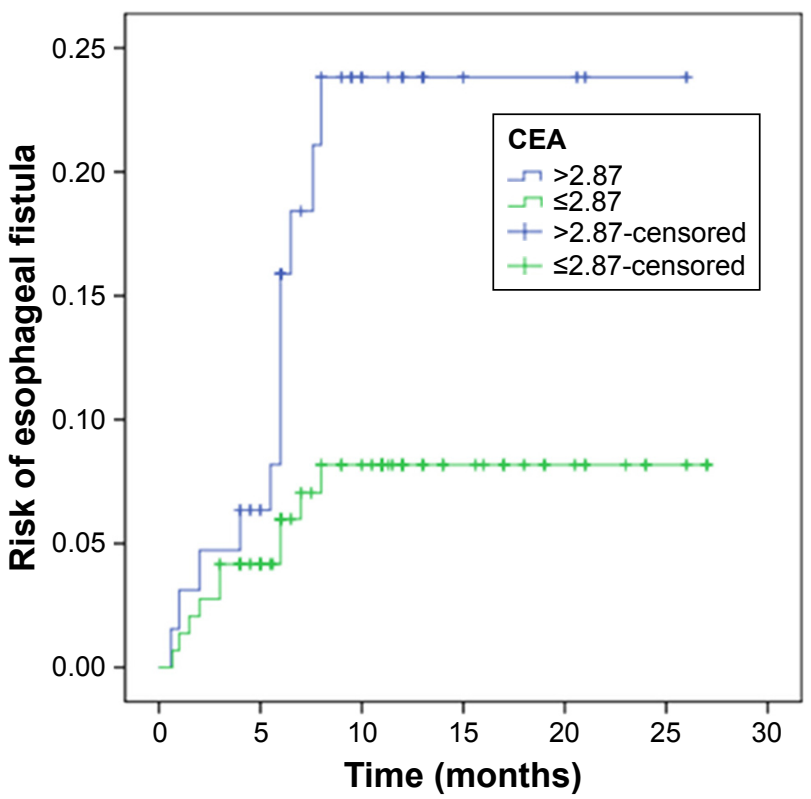

Figure 4 Comparison of the risk of fistula development between patients with carcinoembryonic antigen (CEA) $>2.87 \mathrm{ng} / \mathrm{mL}$ and CEA $\leq 2.87 \mathrm{ng} / \mathrm{mL}(p=0.016)$.

prospective research. In total, 16 clinical parameters were included in the analysis, and esophageal stenosis, $\mathrm{T}$ stage, and CEA were found to be risk factors. The incidence rate of esophageal fistula for patients without stenosis was 4.67\%, and $16.19 \%$ for those with stenosis. Among the 22 patients with fistula, 17 (77.3\%) had stenosis. In patients with stage T4 disease the rate was 2.66 times higher than in those with T2-3. The incidence for patients with CEA $>2.87 \mathrm{ng} / \mathrm{mL}$ was $18.46 \%$, whereas for those with CEA $\leq 2.87 \mathrm{ng} / \mathrm{mL}$ it was only $6.80 \%$.

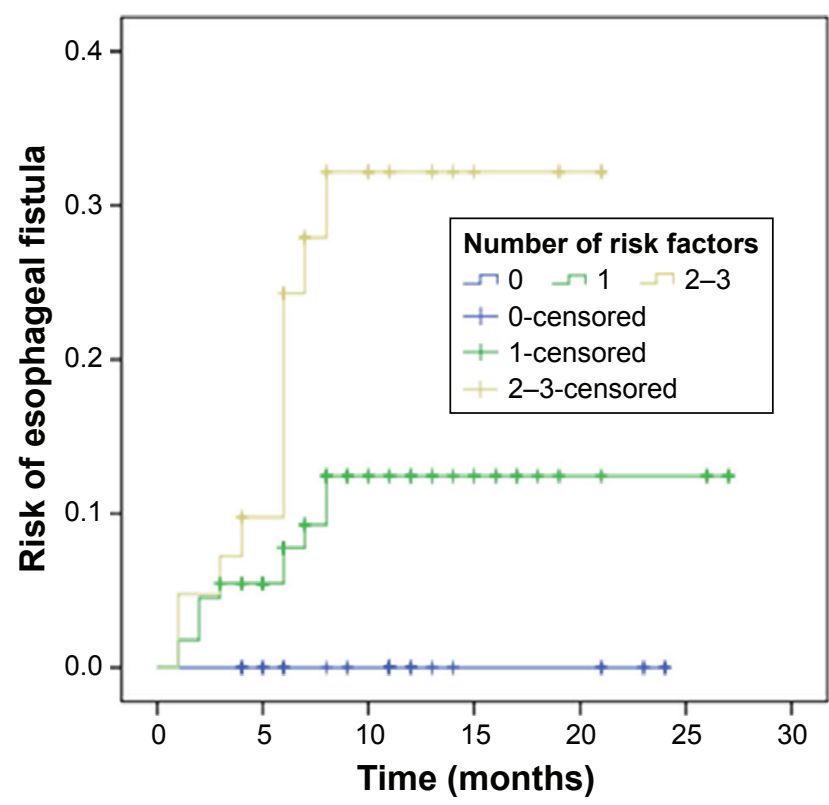

Figure 5 Comparison of the risk of fistula development between patients with different numbers of risk factors $(p=0.000)$. 
As in the research performed by Tsushima et al, ${ }^{11}$ our study also revealed that esophageal stenosis was a significant factor in fistula occurrence. The mechanism of this phenomenon has not been elucidated, although it may be partly attributed to the physical friction of food. In stage T4 EC, the tissues and organs around the esophagus are affected, and previous research also demonstrated that EC patients with cT4 had higher rates of fistula. ${ }^{15,16}$ Therefore, more attention should be given to cT4 patients. CEA, which was first extracted from the tissue of fetal intestine and adult colon carcinoma, ${ }^{17,18}$ is thought to be an important tumor-associated antigen. CEA plays a significant role in the development and progression of many kinds of tumors. ${ }^{19}$ It has been reported to be a useful biomarker in predicting radiosensitivity, occult metastasis, and long-term survival in EC. ${ }^{20-22}$ However, so far there have been no articles investigating the association between CEA and fistula.

To our knowledge, this is the first prospective study to analyze the risk factors for esophageal fistula in patients with locally advanced EC who were treated by chemoradiotherapy. However, there are several limitations to the study. First, while the sample size in this study is relative large, the incidence rate of fistula was not very high; this may be due to the relatively short follow-up time. The number of patients who developed fistula was only 22 , so we could not perform another study to validate the results detected in this set. Second, although almost all parameters investigated in the study were objective, esophageal stenosis was not assessed objectively. Clinicians judged esophageal stenosis based on symptoms and/or patients' reports, not from quantitative objective data. Therefore, in a following study, we aim to establish quantitative criteria for esophageal stenosis and then validate our findings in a large, multicenter population.

\section{Conclusion}

Our study revealed that esophageal stenosis, $\mathrm{T}$ stage, and CEA were risk factors for esophageal fistula. The findings have significant meaning, and in clinical practice, more attention should be given to patients with these parameters. However, large, multicenter studies are needed to confirm this finding.

\section{Acknowledgment}

This work was supported by Shandong Province Natural Science Foundation (ZR2016HM17, ZR2016HB39).

\section{Disclosure}

The authors report no conflicts of interest in this work.

\section{References}

1. Chen W, Zheng R, Baade PD, et al. Cancer statistics in China, 2015. CA Cancer J Clin. 2016;66(2):115-132.

2. Ishida K, Ando N, Yamamoto S, Ide H, Shinoda M. Phase II study of cisplatin and 5-fluorouracil with concurrent radiotherapy in advanced squamous cell carcinoma of the esophagus: a Japan Esophageal Oncology Group (JEOG)/Japan Clinical Oncology Group trial (JCOG9516). Jpn J Clin Oncol. 2004;34(10):615-619.

3. Fujita H. A history of surgery for locally-advanced (T4) cancer of the thoracic esophagus in Japan and a personal perspective. Ann Thorac Cardiovasc Surg. 2013;19(6):409-415.

4. Shinoda M, Ando N, Kato K, et al. Randomized study of low-dose versus standard-dose chemoradiotherapy for unresectable esophageal squamous cell carcinoma (JCOG0303). Cancer Sci. 2015;106(4): 407-412.

5. Cooper JS, Guo MD, Herskovic A, et al. Chemoradiotherapy of locally advanced esophageal cancer: long-term follow-up of a prospective randomized trial (RTOG 85-01). Radiation Therapy Oncology Group. JAMA. 1999;281(17):1623-1627.

6. Gabrail NY, Harrison BR, Sunwoo YC. Chemo-irradiation induced aortoesophageal fistula. J Surg Oncol. 1991;48(3):213-215.

7. Sivaraman SK, Drummond R. Radiation-induced aortoesophageal fistula: an unusual case of massive upper gastrointestinal bleeding. J Emerg Med. 2002;23(2):175-178.

8. Hihara J, Hamai Y, Emi M, et al. Role of definitive chemoradiotherapy using docetaxel and 5-fluorouracil in patients with unresectable locally advanced esophageal squamous cell carcinoma: a phase II study. Dis Esophagus. 2016;29(8):1115-1120.

9. Oh D, Noh JM, Nam H, Lee H, Kim TG, Ahn YC. High-dose radiation therapy alone by moderate hypofractionation for patients with thoracic esophageal squamous cell carcinoma. Medicine (Baltimore). 2016;(33): e4591.

10. Balazs A, Galambos Z, Kupcsulik PK. Characteristics of esophagorespiratory fistulas resulting from esophageal cancers: a single-center study on 243 cases in a 20-year period. World J Surg. 2009;33(5): 994-1001.

11. Tsushima T, Mizusawa J, Sudo K, et al. Risk factors for esophageal fistula associated with chemoradiotherapy for locally advanced unresectable esophageal cancer: a supplementary analysis of JCOG0303. Medicine (Baltimore). 2016;95(20):e3699.

12. Zhou ZG, Zhen CJ, Bai WW, et al. Salvage radiotherapy in patients with local recurrent esophageal cancer after radical radiochemotherapy. Radiat Oncol. 2015;10:54.

13. Freitag L, Tekolf E, Steveling H, Donovan TJ, Stamatis G. Management of malignant esophagotracheal fistulas with airway stenting and double stenting. Chest. 1996;110(5):1155-1160.

14. Rodriguez AN, Diaz-Jimenez JP. Malignant respiratory-digestive fistulas. Curr Opin Pulm Med. 2010;16(4):329-333.

15. Taniguchi H, Yamazaki K, Boku N, et al. Risk factors and clinical courses of chemoradiation-related arterio-esophageal fistula in esophageal cancer patients with clinical invasion of the aorta. Int J Clin Oncol. 2011;16(4):359-365.

16. Nishimura Y, Suzuki M, Nakamatsu K, Kanamori S, Yagyu Y, Shigeoka H. Prospective trial of concurrent chemoradiotherapy with protracted infusion of 5-fluorouracil and cisplatin for T4 esophageal cancer with or without fistula. Int J Radiat Oncol Biol Phys. 2002;53(1): 134-139.

17. Gold P, Freedman SO. Demonstration of tumor-specific antigens in human colonic carcinomata by immunological tolerance and absorption techniques. J Exp Med. 1965;121:439-462.

18. Gold P, Freedman SO. Specific carcinoembryonic antigens of the human digestive system. $J$ Exp Med. 1965;122(3):467-481.

19. Canbay E, Ishibashi H, Sako S, et al. Preoperative carcinoembryonic antigen level predicts prognosis in patients with pseudomyxoma peritonei treated with cytoreductive surgery and hyperthermic intraperitoneal chemotherapy. World J Surg. 2013;37(6):1271-1276. 
20. Yi Y, Li B, Wang Z, Sun H, Gong H, Zhang Z. CYFRA21-1 and CEA are useful markers for predicting the sensitivity to chemoradiotherapy of esophageal squamous cell carcinoma. Biomarkers. 2009;14(7):480-485.

21. Scarpa M, Noaro G, Saadeh L, et al. Esophageal cancer management: preoperative CA19.9 and CEA serum levels may identify occult advanced adenocarcinoma. World J Surg. 2015;39(2): 424-432.
22. Zhang HQ, Wang RB, Yan HJ, et al. Prognostic significance of CYFRA21-1, CEA and hemoglobin in patients with esophageal squamous cancer undergoing concurrent chemoradiotherapy. Asian Pac J Cancer Prev. 2012;13(1):199-203.

\section{Publish your work in this journal}

OncoTargets and Therapy is an international, peer-reviewed, open access journal focusing on the pathological basis of all cancers, potential targets for therapy and treatment protocols employed to improve the management of cancer patients. The journal also focuses on the impact of management programs and new therapeutic agents and protocols on

\section{Dovepress}

patient perspectives such as quality of life, adherence and satisfaction. The manuscript management system is completely online and includes a very quick and fair peer-review system, which is all easy to use. Visit http://www.dovepress.com/testimonials.php to read real quotes from published authors.

Submit your manuscript here: http://www.dovepress.com/oncotargets-and-therapy-journal 